\title{
Dominique Buchillet: caminhos e trilhas no rio Negro e em outros lugares
}

Lúcia Hussak van Velthem e Marcio Meira

\section{Q OpenEdition}

Journals

Edição electrónica

URL: https://journals.openedition.org/jsa/17655

DOI: 10.4000/jsa.17655

ISSN: 1957-7842

Editora

Société des américanistes

\section{Edição impressa}

Data de publição: 20 dezembro 2019

Paginação: 201-209

ISSN: 0037-9174

\section{Refêrencia eletrónica}

Lúcia Hussak van Velthem et Marcio Meira, « Dominique Buchillet: caminhos e trilhas no rio Negro e em outros lugares », Journal de la Société des américanistes [En ligne], 105-2 | 2019, mis en ligne le 20 décembre 2019, consulté le 04 septembre 2022. URL : http://journals.openedition.org/jsa/17655 DOI : https://doi.org/10.4000/jsa. 17655 


\title{
Dominique Buchillet: caminhos e trilhas no rio Negro e em outros lugares
}

\author{
Lúcia Hussak van Velthem e Marcio Meira*
}

Conhecemos Dominique Buchillet há longo tempo. Mais precisamente desde a sua chegada, em 1984, a Belém e ao Museu Paraense Emilio Goeldi (MPEG). Assim como o antropólogo Bruce Albert, Dominique esteve ligada a esta instituição durante alguns anos, atuando no Programa de Pesquisa sobre Ocupação Humana da Amazônia, vinculado a um convênio de cooperação científica que unia o então Office de la recherche scientifique et technique outre-mer $(\mathrm{ORSTOM})^{1}$ ao Conselho Nacional de Desenvolvimento Científico e Tecnológico (CNPq). Na Amazônia, programas de cooperação internacional envolvendo o Orstom foram desenvolvidos em instituições de Belém e também de Manaus, entre as quais o Instituto Nacional de Pesquisas da Amazônia (INPA)², e muito contribuíram para o fortalecimento dos programas científicos dessas instituições.

No torvelinho das lembranças, recordo-me $e^{3}$ que compartilhamos a mesma sala de trabalho durante todo o período em que Dominique esteve em Belém, sala esta que ela perfumava, todas as manhãs, com requintadas essências francesas. Eu não era a sua "responsável" brasileira ${ }^{4}$, mas logo nos tornamos próximas e amigas, tanto por questões de entendimento linguístico em francês como por afinidades intelectuais e interesses culturais. Esse período foi marcado como de intensas trocas minhas com Dominique, trocas estas que se prolongaram durante anos, bem depois de sua partida do Brasil. Permutávamos notícias, ideias, livros de literatura e de antropologia, de artefatos, que incluíam os de procedência

* L. Hussak van Velthem: Museu Paraense Emilio Goeldi (MPEG) - Ministério da Ciência, Tecnologia, Inovações e Comunicações (MCTIC) [luciavelthem@museu-goeldi. br]; M. Meira: Museu Paraense Emilio Goeldi (MPEG) - Ministério da Ciência, Tecnologia, Inovações e Comunicações (MCTIC) [marciomeira@museu-goeldi.br].

1. Em 1998 passou a ser denominado de Institut de recherche pour le développement (IRD).

2. Ver a respeito Toni e Velho (1996), Faulhaber (2005).

3. Os dois autores conheciam Dominique Buchillet, mas a rememoração da introdução se deve exclusivamente a Lúcia van Velthem.

4. O responsável formal pela contrapartida brasileira era Antônio Maria de Souza Santos. 
indígena, os de arte popular brasileira, os africanos e, mais recentemente, de pinturas e tecidos tailandeses.

Os diferentes apartamentos em que Dominique viveu, em Belém, Brasília, Paris, revelavam o seu interesse pela coleção, ou melhor, pelas coleções de livros e objetos de várias procedências, cuja reunião tinha um sentido museológico, porque haviam sido reunidos e eram dispostos de acordo com uma certa ordem. Por outro lado, a minha morada, em Belém, apresenta muitos objetos e livros que remetem à sua lembrança, ao seu gosto refinado e à sua generosidade $\mathrm{e}$, também, ao seu vasto conhecimento antropológico.

As lembranças trazem à mente a grande determinação de Dominique, a sua capacidade de trabalho, em que se revelava incansável. Como esquecer o profundo interesse e a dedicação que tinha ao trabalho de campo, que nesse período se concentrava no rio Negro, onde pesquisou por mais de 20 anos. Dominique gostava sobretudo de estar nas comunidades localizadas nos afluentes do seu alto curso, porque não apreciava trabalhar em São Gabriel da Cachoeira, a sede do município. Os seus intensos e rigorosos trabalhos no alto rio Negro the permitiram reunir uma grande soma de informações, tanto etnográfica como também sobre as fontes históricas, que revelam a sua atenção constante a todos os detalhes e a uma grande diversidade de fontes.

Quando Dominique se mudou para Brasília em 1987, a longa distância ocasionou certo afastamento, e assim nos perdemos um pouco de vista, mas não o intercâmbio. Estive visitando-a uma vez e pude, então, conhecer e desfrutar, passeando pelas longas avenidas de Brasília, de sua última aquisição, um Karmann Ghia bicolor. Retrospectivamente, creio que o período brasiliense de Dominique foi o mais interessante e completo de sua estada no Brasil, para o qual contribuiu o fato de morar bem próximo ao Cine Brasília e assim poder assistir aos filmes de arte que tanto apreciava.

De Brasília, Dominique retornou à França e ao seu trabalho no Institut de recherche pour le développement (IRD). Nesse período, voltou-se para o estudo da medicina chinesa, tendo se dedicado com afinco ao aprendizado da escrita ideográfica que lhe permitiria a leitura de documentos sobre as terapêuticas chinesas. Não pôde, contudo, trabalhar na China e, por este motivo, instalou-se durante vários anos na Tailândia, país fronteiriço que lhe permitiu o acesso a uma vasta documentação. De volta à França, aposentou-se há alguns anos.

Visitando-a em 2012 em Paris, pude constatar que o seu interesse pela Amazônia e os povos indígenas do rio Negro não havia arrefecido, pois mantinha a atenção voltada para a pesquisa nesta região. Lembro-me que na ocasião mencionou a possibilidade de realizar um trabalho de síntese sobre assuntos relacionados com a antropologia da doença na região do rio Negro. Este perene interesse pode ser comprovado através de publicações recentes, entre as quais se destaca "Colonization and epidemic diseases in the upper Rio Negro region, 
Brazilian Amazon (Eighteenth-Nineteenth centuries)", de 2018, o ano de sua morte. Nessa mesma visita ao seu amplo apartamento, apresentou-me um belíssimo armário chinês lavrado, adquirido na estadia asiática, e destinado ao armazenamento de remédios, de poções e, portanto, dotado de múltiplas pequenas gavetas. O que continham não me recordo mais, mas me lembro muito bem do entusiasmo e do orgulho de Dominique pela compra desse gaveteiro.

\section{Os caminhos do rio Negro}

Dominique Buchillet chegou ao rio Negro conduzida pela antropóloga Berta Ribeiro, que realizava, desde 1978, pesquisas entre os Desana, povo indígena de língua tukano oriental, habitantes da comunidade de São João no rio Tiquié, afluente do rio Uaupés. Assim como Berta Ribeiro, Dominique trabalhou com os Desana desta mesma comunidade e também com aqueles que viviam nos igarapés Umari, Urucu e Cucura, onde estava estabelecido um de seus principais interlocutores, Dorvalino Fernandez. Realizou ainda pesquisas entre os Tariana de Iauareté .

Suas pesquisas sobre concepções de doença enveredaram pelo universo dos conhecimentos xamânicos e masculinos dos Desana, mas sem se limitar a este tema. Esses trabalhos resultaram na produção de sua tese de doutorado, "Maladie et mémoire des origines chez les Desana du Uaupés brésilien. Conceptions de la maladie et de la thérapeutique d'une société amazonienne", que foi defendida em 1983 na Université Paris X (Nanterre). Trata-se de um trabalho seminal, infelizmente ainda não publicado, e que é indubitavelmente a sua obra mais referida.

A partir de seu doutorado, Dominique se impôs a compreensão profunda da medicina tradicional, na qual as curas xamânicas têm um papel fundamental e a recitação de encantações terapêuticas, altamente formalizadas, são percebidas como capazes de interferir diretamente no corpo da pessoa doente. Como destaca na introdução de "Medicinas tradicionais e medicina ocidental na Amazônia", que editou e publicou em 1991, a concepção indígena da eficácia terapêutica de um tratamento xamânico inclui dois polos de extensão variável: o do sentido comum universal e o do tratamento simbólico dos eventos que escapam ao primeiro. Desta forma, seria impossível diferenciar o empírico, o natural ou o objetivamente eficaz do mágico religioso, natural ou simbólico, porque os resultados se inseririam na lógica simbólica e esta nunca contradiz a experiência e, mesmo, se fundamenta parcialmente nela.

A antropologia da doença representa, portanto, a sua principal linha de pesquisa e através dela buscou compreender, entre os povos indígenas do rio Negro, os sistemas de saúde tradicional e o ocidental e a questão de sua articulação.

5. Ver o texto rememorativo de Cabalzar (2018) para mais detalhes. 
Os seus estudos contribuem de modo decisivo para a renovação da antropologia da doença, através de ramificações intelectuais que se ancoram no rigor de suas pesquisas, cujas inferências conduzem a novas direções. Sobre esta temática abordou assuntos variados, traçando novas vias de entendimento, algumas das quais de modo pioneiro.

Dessa forma, naquele momento, as preocupações com a grave situação sanitária e com as ameaças aos direitos territoriais dos povos indígenas do rio Negro constituíram as duas vertentes, ambas de natureza ética e política, que podem ser identificadas como as razões que moveram Dominique a relacionar, nos seus escritos posteriores, a antropologia e a história. Ela também teve a influência dos estudos de história indígena que despontavam no Brasil desde 1988 e que culminaram com a publicação da histórica coletânea organizada por Manuela Carneiro da Cunha em 1992, "História dos Índios no Brasil".

Neste sentido, pode-se afirmar que seu trabalho se apoia largamente no uso de uma rígida metodologia de pesquisa e de técnicas de documentação próprias. Entretanto, soube de modo magistral colocar o campo das suas pesquisas americanistas na interface da antropologia e da história, o que lhe permitiu desenvolver conexões e apresentar inferências complexas, mas sempre originais, que se abriram para uma dimensão teórica mais global. Dominique contribuiu, assim, de forma relevante com os estudos de história indígena no rio Negro. Em 2016 estava trabalhando com os inúmeros documentos históricos sobre aquela região, que ela havia coletado no Brasil entre 1984 e 2004, em vários arquivos e bibliotecas, inclusive nos arquivos dos Salesianos em São Gabriel da Cachoeira, retomando seus trabalhos publicados nos anos 1990 e 2000.

Deve ser ressaltado que, nos trabalhos publicados, uma característica marcante de Dominique é a economia na citação de seus trabalhos, no que pode ser chamado de autorreferenciamento. Quando se consultam as referências em seus trabalhos, encontram-se apenas uma, duas ou no máximo três indicações de artigos seus produzidos anteriormente. Por outro lado, é quase sempre exaustiva a lista de obras que tratam do assunto em pauta.

\section{Outros caminhos trilhados}

As andanças e as pesquisas de Dominique no rio Negro tiveram outros efeitos, além dos acadêmicos, e assim se destaca o fato de que ela foi muito atuante no campo da antropologia médica. Contribuiu com artigos científicos e também com políticas adaptadas aos povos indígenas e sistematizou os conhecimentos nessa área. Produziu ainda diversos relatórios de avaliação de projetos de saúde, culturalmente sensíveis, em áreas indígenas na Amazônia. Suas preocupações acadêmicas, nesse sentido, se vinculavam com as suas perplexidades sobre a precária situação sanitária em que viviam os povos indígenas do rio Negro, que a antropóloga pôde vivenciar em suas pesquisas de campo, desde o final 
dos anos 1970, sobretudo em relação aos inúmeros casos de tuberculose. Esta preocupação se evidencia nos relatórios que Dominique elaborou em 1998 sobre a situação epidemiológica mais geral e a tuberculose em particular na região do rio $\mathrm{Negro}^{6}$.

Entretanto, a partir de 1985, durante a chamada "transição democrática", iniciou-se a implantação do Projeto Calha Norte. Dominique, que encontrava então dificuldades burocráticas na Fundação Nacional do Índio (Funai) para realizar suas pesquisas de campo, dedicou-se tenazmente à efetivação dos direitos dos povos indígenas, denunciando o Projeto Calha Norte e sua atuação no alto rio Negro nos anos 1980. Neste campo, sua primeira análise data de 1986, quando publicou "Droits territoriaux, raisons de sécurité nationale et politique indigéniste au Brésil". Entretanto, o mais conhecido e completo de seus escritos sobre o tema está consignado em "Pari-Cachoeira: le laboratoire Tukano du Projet Calha Norte”, publicado em 1990, inicialmente em francês, e um ano depois em português.

Os povos indígenas do rio Negro reivindicavam a demarcação integral de seus territórios tradicionais, o que gerou uma forte controvérsia político-jurídica sobre a forma em que se dariam as demarcações, pois o governo federal não aceitava reconhecer um território único e contínuo. Esta querela só foi resolvida em favor dos povos indígenas após 1988, com a promulgação da nova Constituição brasileira. Nessa linha, a atuação indigenista mais relevante de Dominique foi a elaboração do laudo antropológico que escreveu a pedido do Ministério Público Federal (MPF), entregue em 1990, e depois atualizado e ampliado em 1997: "Os Índios da Região do Alto Rio Negro: História, Etnografia e Situação das Terras", que embasou o relatório circunstanciado da Funai para a delimitação e posterior demarcação da Terra Indígena Alto Rio Negro, homologada em 1998, uma significativa conquista do movimento indígena rionegrino. Nesses textos, Dominique se engajou ativamente na análise crítica do indigenismo oficial que ainda vigorava na Funai, mesmo após a ditadura militar, e na formulação dos argumentos antropológicos e históricos que embasavam as reivindicações indígenas em função de um novo contexto político no Brasil.

O livro "Antes o mundo não existia", a respeito da mitologia desana, foi escrito e assinado por protagonistas indígenas e coordenado por Berta Ribeiro, tendo sido publicado em 1980. Dominique colaborou na reedição deste livro, o primeiro volume da série "Narradores Indígenas do Rio Negro. Memória, Identidade, Patrimônio cultural e Perspectivas para o Futuro", editada pela

6. Ver, por exemplo, "Levantamento e avaliação de projetos de saúde em áreas indígenas da Amazônia legal. Suporte a projetos de saúde culturalmente sensíveis" (Relatório de consultoria para o PPTAL/GTZ/ Banco Mundial, 71 p.); e "Fatores socioculturais e econômicos de risco para HIV e Tuberculose na região do alto Rio Negro (Amazônia Brasileira)" (Relatório n. 1 CNPq/Orstom n. 910213/97-6). 
Federação das Organizações Indígenas do Rio Negro (Foirn) e o Instituto Socioambiental (ISA), a partir de 1995. Particularmente interessada por este projeto, Dominique coordenou a edição de quatro dos oito volumes que integram até o presente esta coleção, tendo ainda contribuído para a revisão técnica de outros três livros que apresentam a mitologia sagrada dos Desana. Nesta coleção, o primeiro volume (1996) é dedicado à mitologia sagrada dos Desana-Wari Dihputiro Põrã, o segundo (2000) enfoca as narrativas míticas dos Tariana e inclui importante depoimento sobre a chegada dos brancos nesta mesma região. Um terceiro livro (2004) é referente aos Desana-Guahari Diputiro Porã, e o quarto (2006) aborda os "ensinamentos que não se esquecem" e apresenta a história das constelações e diferentes tipos de rituais e festividades. O primeiro e o quarto volumes narram a formação do mundo, a transformação da humanidade e a chegada dos ancestrais dos povos indígenas atuais ao rio Negro.

\section{Os caminhos das miçangas e das doenças}

$\mathrm{Na}$ impossibilidade de comentar de forma detalhada o conjunto da obra de Dominique Buchillet, escolhemos destacar, entre todos os seus escritos, um que apreciamos especialmente. Trata-se do artigo que enfoca aspectos relacionados com as mercadorias que advêm através do contato e que se associam às epidemias: "Contas de vidro, enfeites de branco e 'potes de malária'. Epidemiologia e representações de doenças infecciosas entre os Desana no Rio Negro", publicado em 2002 em uma coletânea organizada por Bruce Albert e Alcida Rita Ramos e intitulada "Pacificando o branco. Cosmologia do contato no Norte-Amazônico". Anteriormente, em 1995, dois artigos de títulos análogos: "Perles de verre, parures de Blancs et 'pots de paludisme'. Épidémiologie et représentations Desana des maladies infectieuses" (Haut Rio Negro, Brésil) e "Contas de vidro, enfeites de branco e 'potes de malária': epidemiologia e representações de doenças infecciosas entre os Desana" foram publicados, o primeiro no Journal de la Société des américanistes, periódico pelo qual Dominique devotava certa predileção, como comprova o levantamento de sua produção acadêmica, e o outro na Universidade de Brasília, "Série Antropologia".

A coletânea "Pacificando o branco", segundo seus organizadores, visava ampliar o foco da observação etnográfica tanto em relação à diversidade de regimes expressivos e dimensões sociais pelos quais as sociedades indígenas do norte da Amazônia constroem sua articulação com a fronteira envolvente quanto da descrição do pensamento indígena sobre os fatos e os efeitos das "situações de contato". Destacaram ainda que a penetração dos objetos manufaturados e os germes patológicos nas culturas indígenas constituem aspectos fundamentais do contato entre brancos e índios desde os primeiros encontros. No plano histórico, as doenças infecciosas e os brancos tornam-se indissolúveis, as primeiras 
assumindo um papel determinante na conquista e na colonização do Novo Mundo, causando grande impacto sobre as populações indígenas das Américas.

Em seu artigo, Dominique traça um painel da epidemiologia do contato entre os Desana, buscando interpretar à luz das representações xamânicas certos aspectos das doenças infecciosas que resultaram do encontro desses povos indígenas com os brancos. Neste sentido, Bruce Albert (2002, p. 13) destaca que o texto de Dominique demonstra como a teoria etiológica dos Desana, ao cruzar características das situações de contato (trocas e contaminações, patogenia seletiva) e propriedades epidemiológicas das novas doenças, vai interpretar a potência de contágio como manifestações do exorbitante poder (re)produtivo dos brancos, cuja proliferação autossuficiente leva à aniquilação do Outro.

A argumentação do artigo de Dominique indica que as representações das doenças dependem da história específica do contato das sociedades afetadas, bem como de características do ecossistema que favoreceram a sua emergência e propagação. A análise se baseia em certo contexto colonial e na virulenta contaminação ocorrida através de epidemias de sarampo, varíola, gripe e malária, que desde o século XVIII afligem os Desana. No artigo, Dominique indica que a simbolização xamânica deste povo indígena a respeito dessas quatro doenças se baseia em considerações sobre a experiência histórica do contato interétnico e também sobre a principal característica das patologias associadas especificamente aos brancos - sarampo, varíola e gripe - e que vem a ser o seu grande poder de contágio e a maneira seletiva com que essas doenças atacam índios e brancos. Esses aspectos remetem a uma diferença radical entre as duas sociedades, e que está inscrita no mito de origem dos Desana. Segundo a narrativa mítica, os brancos adquiriram extrema capacidade de reprodução de si mesmos, de seus objetos manufaturados e também de suas doenças. Uma versão ${ }^{7}$ descreve como as primeiras mulheres brancas recolheram de uma árvore as contas de vidro para fabricar colares que em seguida ofereceram às mulheres indígenas, as quais pouco depois ficaram doentes.

Como Dominique destaca - de forma pioneira - em seu artigo, as experiências vividas com a introdução dos bens dos brancos, como é caso das contas de vidro, levaram os Desana a associá-las aos exantemas do sarampo e da varíola. Uma variante do mito indica que as miçangas pequenas são responsáveis pelas manifestações cutâneas do sarampo, e as maiores, pelos exantemas da varíola. O paralelismo entre doenças e contas de vidro é igualmente determinado pelos Mamaindê, que explicam os estados mórbidos como ocasionados pelo rompimento dos colares de contas que as pessoas possuem no interior de seus corpos (Miller 2018, p. 110).

7. Trata-se da versão de Luis Lanna do sib Kehiri-poda do rio Tiquié. 
As contas de vidro ou miçangas desempenharam um papel relevante em muitas esferas das trocas operadas entre os povos indígenas e os brancos nas primeiras fases do contato. O interesse por essas contas se perpetua até os dias atuais e se reveste de variado sentido. Entre os povos indígenas, a utilização de miçangas se manifesta em diversos registros culturais, efetivados por meio de construções simbólicas, geralmente integradas à dinâmica mitológica, que explicam a sua procedência e as características relevantes, tais como a durabilidade, a abundância e também os seus poderes deletérios (Velthem 2010). Nos dias atuais e nas arenas políticas das grandes cidades, as miçangas, enquanto significativos elementos de ornamentação corporal, revestem-se de uma nova eficácia na afirmação de identidades indígenas.

Em seu artigo, Dominique especifica que apenas os indígenas foram atingidos pelos surtos de sarampo e varíola, o que tem um fundamento histórico e epidemiológico. Os brancos (militares, missionários, colonos) que invadiram a região do rio Negro no século XVIII aparentavam uma vitalidade que contrastava com a alta mortalidade dos indígenas, o que teve um profundo impacto na conceituação de suas doenças, constituindo uma dimensão fundamental da percepção histórica dos brancos e de seus objetos manufaturados.

As questões acadêmicas de Dominique Buchillet, como vimos acima, estiveram sempre balizadas pela articulação entre os problemas indigenistas, marcadamente a situação sanitária e fundiária dos povos indígenas do alto rio Negro, com os temas relacionados à história do contato e da antropologia médica, sendo esta combinação de agências que definiu melhor o caráter da sua atuação rigorosa e ética. Há poucos registros fotográficos de Dominique, mas a sua imagem está profundamente gravada no coração de todos aqueles que tiveram a oportunidade de conviver com uma pessoa profundamente dedicada aos estudos antropológicos e à causa indígena.

\section{Referências citadas}

Albert Bruce

2002 "Introdução: cosmologias do contato no Norte-Amazônico", in Bruce Albert e Alcida Rita Ramos (orgs), Pacificando o branco. Cosmologias do contato no Norte-Amazônico, Editora UNESP/Imprensa Oficial do Estado/IRD, São Paulo.

Cabalzar Aloisio

2018 "Morre a antropóloga Dominique Buchillet”, Blog do Rio Negro, ISA, São Paulo, https://www.socioambiental.org/pt-br/blog/blog-do-rio-negro/morre-a-antropologa-dominique-buchillet, consultado em 02/12/19.

Carneiro da Cunha Manuela (org.)

1992 História dos índios no Brasil, Companhia das Letras, Secretaria Municipal de Cultura, FAPESP, São Paulo. 
Dominique Buchillet: caminhos e trilhas no rio Negro e em outros lugares

FAULhaber Priscila

2005 "A história dos institutos de pesquisa na Amazônia", Estudos Avançados, 19 (54), p. 241-257.

MiLler Joana

2018 As coisas. Os enfeites corporais e a noção de pessoa entre os Mamaindê (Nambiquara), Mauad, FAPERJ, Rio de Janeiro.

Ribeiro Berta G. (org.)

1980 Antes o mundo não existia. A mitologia heroica dos índios Desana, Umúsin Panlõn Kumu, Tolamã Kenhíri (narradores), Livraria Cultura Editora, São Paulo.

Toni Fabiano e Léa VelHo

1996 "A presença francesa no Instituto Nacional de Pesquisas da Amazônia - INPA", Interciência, 21 (1), p. 25-30.

Velthem Lúcia Hussak van

2010 “Os 'originais' e os 'importados': referências sobre a apreensão wayana dos bens materiais", Indiana, 27, p. 141-159. 
